\title{
SPL Pharmaceutical Dosage Form Terminology
}

National Cancer Institute

\section{Source}

National Cancer Institute. SPL Pharmaceutical Dosage Form Terminology. NCI

Thesaurus. Code C54456.

Terminology used for representation of the information on pharmaceutical product dosage form in the framework of the Structured Product Labeling documents. 